\title{
Mycoleptione, a new chromone derivative isolated from the endophytic fungus Mycoleptodiscus sp. MU41
}

\author{
Ratklao Siriwach ${ }^{1}$, Hiroshi Kinoshita ${ }^{1}$, Shigeru Kitani ${ }^{1}$, Yasuhiro Igarashi ${ }^{2}$, Kanokthip Pansuksan ${ }^{3}$, \\ Watanalai Panbangred ${ }^{3}$ and Takuya Nihira ${ }^{1,4}$
}

The Journal of Antibiotics (2012) 65, 627-629; doi:10.1038/ja.2012.80; published online 24 October 2012

Keywords: mycoleptodiscus; endophytic fungi; chromone

Endophytic fungi colonizing plants produce a wide variety of compounds, possibly because the plant environment stimulates them to synthesize bioactive compounds in order to adapt or be of benefit to their hosts, and hence they have been considered an excellent source for the discovery of novel secondary metabolites. ${ }^{1,2}$ Thailand, which is located in a tropical zone, has high biodiversity, especially in plants, and thus is one of the promising countries for obtaining endophytes. As some of the biological activity of the plants used for medicinal purposes might be attributed to the microbes inhabiting the plants, particular attention has been paid to the endophytes, and consequently several novel compounds have been obtained. ${ }^{3-6}$

During our preliminary screening to discover structurally novel secondary metabolites of endophytic fungi isolated from Thai medicinal plants, ${ }^{7}$ an endophytic fungus, Mycoleptodiscus sp., was isolated from Tinospora crispa. T. crispa has been used as traditional medicine in rural society in Thailand in order to treat fever, cholera, snake bites, rheumatism and fever due to malaria. Furthermore, this plant is currently being investigated for its antioxidant, antidiabetic, antimalarial and cosmetic effects. 8

The genus Mycoleptodiscus that is classified as a plant-associated fungus has also attracted great attention because of its several interesting abilities. For example, several reports have proposed that Mycoleptodiscus terrestris can be used as a biological control agent for management of the world's aquatic weeds, including hydrilla and Eurasian watermilfoil, ${ }^{9-11}$ and that Mycoleptodiscus indicus produces the compound eugenitin, which can activate glucoamylase from Aspergillus niveus. ${ }^{12}$ Based on these facts, Mycoleptodiscus spp. might be regarded as an interesting unexplored target for screening novel secondary metabolites.

The preliminary screening for novel compounds with HPLC-DAD analysis detected two unknown metabolites in $n$ - $\mathrm{BuOH}$ extract from the static culture of Mycoleptodiscus sp. MU41 (cultured in $10 \mathrm{ml}$ of medium
6 in a test tube $($ size $\varnothing 16 \times 150 \mathrm{~mm})$ for 21 days at $28^{\circ} \mathrm{C}$ ) (Supplementary S2), which have the maximum UV absorption at $210,242,250,288 \mathrm{~nm}$ and 204, 256, $380 \mathrm{~nm}$, respectively. As the comparison of those spectra with the data registered in our in-house database suggested the discovery of new compounds and only limited metabolites have been reported from Mycoleptodiscus sp., we determined to isolate and identify the compounds from Mycoleptodiscus sp. MU41.

The mycelia of Mycoleptodiscus sp. MU41 was inoculated into $100 \mathrm{ml}$ of medium 6 (glucose 1\%, mannitol 10\%, pharmamedia (Southern Cotton Oil Co., Memphis, TN, USA) 3.5\%, $\mathrm{KH}_{2} \mathrm{PO}_{4} 0.9 \%$ ) in $500-\mathrm{ml}$ baffled flasks, and cultivated for 21 days at $28^{\circ} \mathrm{C}$ under a static condition to obtain $\mathbf{1}$ and under an agitated condition on a reciprocal shaker at 120 r.p.m. to yield 2. After static cultivation, the cultures $(100 \mathrm{ml} \times 20$ flasks) were extracted with an equal amount of EtOAc, which was then evaporated to afford a crude extract (brown gum, $4 \mathrm{~g}$ ). The crude extract was separated on a $\mathrm{C}_{18}$ chromatograph column by stepwise elution with increasing $\mathrm{MeOH}$ concentrations $\left(\mathrm{MeOH} / \mathrm{H}_{2} \mathrm{O}=0: 10,2: 8,4: 6,5: 5,6: 4,8: 2,9: 1\right.$ and 10:0 v/v). The 50\% $\mathrm{MeOH}$ fractions containing compound 1 were evaporated $(67.7 \mathrm{mg})$. Compound 1 was further purified by preparative reversed-phase HPLC with a shallow $\mathrm{MeOH}$ gradient in $0.1 \%$ trifluoroacetic acid (a $55-65 \% \mathrm{MeOH}$ gradient over a period of $20 \mathrm{~min}$ ), yielding pure 1 $(6.1 \mathrm{mg})$. To obtain 2 from the agitated culture, the whole culture $(200 \mathrm{ml})$ was directly filtrated by filter paper $(90 \mathrm{~mm}$; Advantec, Tokyo, Japan). The culture filtrate $(125 \mathrm{ml})$ was subjected to HP-20 (Mitsubishi Chemical Co., Tokyo, Japan) column chromatography and was fractionated by stepwise elution with increasing $\mathrm{MeOH}$ concentrations $\left(\mathrm{MeOH} / \mathrm{H}_{2} \mathrm{O}=2: 8,4: 6,6: 4,8: 2\right.$ and 10:0 v/v). The 60 and $80 \% \mathrm{MeOH}$ fractions containing 2 were combined and evaporated. The residue $(61.8 \mathrm{mg})$ was further purified by two rounds of preparative reversed-phase HPLC; the first round was conducted with an $\mathrm{MeOH}$ gradient in $0.1 \%$ trifluoroacetic acid (a $30-100 \% \mathrm{MeOH}$

${ }^{1}$ International Center for Biotechnology, Osaka University, Suita, Japan; ${ }^{2}$ Biotechnology Research Center, Toyama Prefectural University, Imizu, Japan; ${ }^{3}$ Department of Biotechnology, Mahidol University, Bangkok, Thailand and ${ }^{4} \mathrm{MU}-\mathrm{OU}$ Collaborative Research Center for Bioscience and Biotechnology, Mahidol University, Bangkok, Thailand Correspondence: Professor T Nihira, International Center for Biotechnology, Osaka University, 2-1 Yamadaoka, Suita, Osaka 565-0871, Japan.

E-mail: nihira@icb.osaka-u.ac.jp

This is a part of the doctoral dissertation of RS.

Received 1 June 2012; revised 1 September 2012; accepted 7 September 2012; published online 24 October 2012 
Table 1 NMR spectroscopic data of mycoleptione (1) in $\mathrm{CD}_{3} \mathrm{OD}$

\begin{tabular}{|c|c|c|c|c|}
\hline Position & $\delta_{C}$ & $\delta_{H}$ & $\mathrm{HH}-\mathrm{COSY}$ & $H M B C$ \\
\hline 2 & 167.4 & - & & \\
\hline 3 & $112.5(\mathrm{CH})$ & 6.06 (s) & & $\mathrm{C}-2, \mathrm{C}-10, \mathrm{C}-1^{\prime}$ \\
\hline 4 & 182.0 & - & & \\
\hline 5 & 143.6 & - & & \\
\hline 6 & $118.0(\mathrm{CH})$ & $6.62(\mathrm{dd}, J=2.2 \mathrm{~Hz})$ & $\mathrm{H}-\left(5-\mathrm{CH}_{3}\right)$ & $\mathrm{C}-8, \mathrm{C}-10,5-\mathrm{CH}_{3}$ \\
\hline 7 & 163.0 & - & & \\
\hline 8 & $101.7(\mathrm{CH})$ & $6.65(\mathrm{~d}, J=2.2 \mathrm{~Hz})$ & & C6, c9 \\
\hline 9 & 161.5 & - & & \\
\hline 10 & 115.9 & - & & \\
\hline $5-\mathrm{CH}_{3}$ & $23.1\left(\mathrm{CH}_{3}\right)$ & $2.71(\mathrm{~s})$ & $\mathrm{H}-6$ & $C-5, C-6, C-10$ \\
\hline \multirow[t]{2}{*}{$1^{\prime}$} & $42.4\left(\mathrm{CH}_{2}\right)$ & $\begin{array}{c}2.60(\mathrm{dd}, J=8.7 \\
14.5 \mathrm{~Hz})\end{array}$ & $\mathrm{H}-2^{\prime}$ & C-2, C-3, C-2', C-3' \\
\hline & & $\begin{array}{c}2.76(\mathrm{dd}, J=4.0 \\
14.5 \mathrm{~Hz})\end{array}$ & $\mathrm{H}-2^{\prime}$ & $\mathrm{C}-2, \mathrm{C}-3, \mathrm{C}-2^{\prime}$ \\
\hline $2^{\prime}$ & $71.5(\mathrm{CH})$ & $3.91(\mathrm{~m})$ & $\mathrm{H}-1^{\prime}, \mathrm{H}-3^{\prime}$ & \\
\hline $3^{\prime}$ & $31.2\left(\mathrm{CH}_{2}\right)$ & $1.57(\mathrm{~m})$ & $\mathrm{H}-2^{\prime}, \mathrm{H}-4^{\prime}$ & $\mathrm{C}-2^{\prime}, \mathrm{C}-1^{\prime}, \mathrm{C}-4^{\prime}$ \\
\hline $4^{\prime}$ & $10.3\left(\mathrm{CH}_{3}\right)$ & $1.01(\mathrm{t}, J=7.4 \mathrm{~Hz})$ & $\mathrm{H}-3^{\prime}$ & $\mathrm{C}-3^{\prime}, \mathrm{C}-2^{\prime}$ \\
\hline
\end{tabular}

${ }^{1} \mathrm{H},{ }^{13} \mathrm{C}$ NMR and 2D NMR spectra were obtained on JOEL JNM-ECS400 NMR spectrometers, in $\mathrm{CD}_{3} \mathrm{OD}$ at room temperature, and the solvent peak was used as an internal standard $\left(\delta_{\mathrm{H}} 3.31\right.$ and $\delta_{\mathrm{C}} 49.0$ in $\left.\mathrm{CD}_{3} \mathrm{OD}\right)$.

gradient over a period of $35 \mathrm{~min})(12.6 \mathrm{mg})$; the second round was performed with a shallow $\mathrm{MeOH}$ gradient in $0.1 \%$ trifluoroacetic acid (a $35-45 \% \mathrm{MeOH}$ gradient over a period of $20 \mathrm{~min}$ ), yielding pure 2 (8.1 mg).

Compound (1) was obtained as a yellow powder. The molecular formula was determined to be $\mathrm{C}_{14} \mathrm{H}_{16} \mathrm{O}_{4}$ based on high-resolution electron impact mass spectrometry (obs. $\mathrm{m} / z$ 248.1046 [M] ${ }^{+}$, calcd. 248.1043 for $\mathrm{C}_{14} \mathrm{H}_{16} \mathrm{O}_{4}$ ), and ${ }^{1} \mathrm{H}$ and ${ }^{13} \mathrm{C}$ NMR spectra data (Table 1). The IR spectrum showed a broadened $\mathrm{OH}$ absorption at $3398 \mathrm{~cm}^{-1}$. The ${ }^{1} \mathrm{H}$ NMR spectrum of $\mathbf{1}$ indicated two methyl signals at $\delta 1.01(\mathrm{t}$, $J=7.4 \mathrm{~Hz}, 3 \mathrm{H})$ and $2.71(\mathrm{~s}, 3 \mathrm{H})$, two methylene protons at $\delta 1.57(\mathrm{~m}$, $2 \mathrm{H}), 2.60(\mathrm{dd}, J=8.7,14.5 \mathrm{~Hz}, 1 \mathrm{H})$ and $2.76(\mathrm{dd}, J=4.0,14.5 \mathrm{~Hz}$, $1 \mathrm{H})$, one methine proton at $\delta 3.91(\mathrm{~m}, 1 \mathrm{H})$ and three aromatic protons at $\delta 6.06(\mathrm{~s}, 1 \mathrm{H}), 6.62(\mathrm{~d}, J=2.2 \mathrm{~Hz})$ and $6.65(\mathrm{~d}, J=2.2 \mathrm{~Hz}$, $1 \mathrm{H})$. The ${ }^{13} \mathrm{C}$ NMR and DEPT data of 1 revealed the presence of 14 carbon signals, including one carbonyl carbon at $\delta$ 182.0, five quaternary carbons at $\delta 115.9,143.6,161.5,163.0$ and 167.4, two methyl carbons at $\delta 10.3$ and 23.1, two $s p^{3}$ methylene carbons at $\delta$ 31.2 and 42.4 , one $s p^{3}$ methine carbon at $\delta 71.5$ and three $s p^{2}$ methine carbons at $\delta 101.7,112.5$ and 118.0. In addition to the characteristic UV and IR spectra, such as the maximum UV absorption at 242, 250 and $288 \mathrm{~nm}$, and a strong absorption band at $1645 \mathrm{~cm}^{-1}$ in the IR spectrum, ${ }^{13}$ the observed carbon signals at $\delta 101.7,112.5,115.9$, 118.0, 143.6, 161.5, 163.0, 167.4 and 182.0 in the ${ }^{13} \mathrm{C}$ NMR spectrum suggested the presence of a 5, 7-disubstituted chromone moiety. ${ }^{14}$ The complete structure of 1 was deduced by comprehensive interpretation of its ${ }^{1} \mathrm{H},{ }^{13} \mathrm{C}$ NMR, HH-COSY, HSQC and HMBC spectra and other spectroscopic data.

The physicochemical data of $\mathbf{1}$ resembled those of the first chromone compound (compound IV; Figure 1) reported by Kashiwada et al., ${ }^{13}$ except for the signals (C-3' $\delta 42.4$ and C- $4^{\prime} \delta$ 10.3 ) originating from the ethyl group connected to the $\mathrm{C}-2^{\prime}$, while a methyl group was attached in compound IV. The substitution of the methyl group in compound IV for an ethyl group at the 2-hydroxybutyl chain was further confirmed by HH-COSY correlation of $\mathrm{H}-3^{\prime}(\delta 1.57)$ with $\mathrm{H}-2^{\prime}(\delta 3.91)$, and also by longrange correlation of $\mathrm{H}-3^{\prime}(\delta 1.57)$ with $\mathrm{C}-2^{\prime}(\delta 71.5)$. Judging from

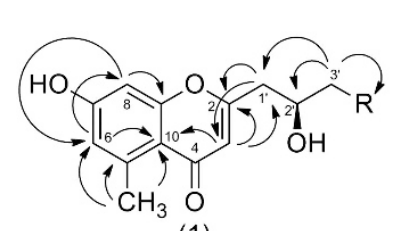

(1)

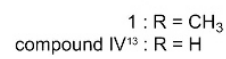

Figure 1 Structure of mycoleptione (1), compound VI,7-epiaustdiol (2).

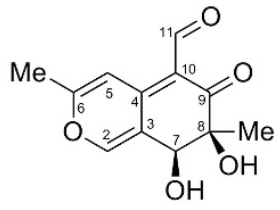

(2)

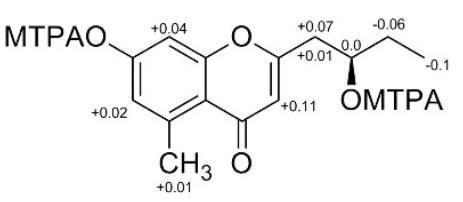

(1)

Figure $2 \Delta \delta \mathrm{S}-R$ values of MTPA esters of mycoleptione (1).

these data, the structure of compound $\mathbf{1}$ was assigned as a chromone bearing a 2-hydroxybutyl chain.

The absolute configuration at C-2' was deduced by the Mosher ester method. ${ }^{15}$ Negative $\Delta \delta$ S-R values were observed for $\mathrm{H}-3^{\prime}(-0.06)$ and $\mathrm{H}-4^{\prime}(-0.1)$, while positive $\Delta \delta \mathrm{S}$ - $\mathrm{R}$ values were observed for H-1' $(+0.01,+0.07), \mathrm{H}-3(+0.11), \mathrm{H}-6(+0.02), \mathrm{H}-8$ $(+0.04)$ and $\mathrm{H}-5-\mathrm{CH}_{3}(+0.01)$, indicating a $2^{\prime} \mathrm{R}$ absolute configuration for 1 (Figure 2 and Supplementary S8). Consequently, the structure of 1 was determined to be $(R)$-7-hydroxy-2-(2-hydroxybutyl)-5-methyl- $4 H$-chromen-4-one and compound 1 was designated as mycoleptione (Figure 1).

Compound (1): a yellow powder; $[\alpha]_{\mathrm{D}}^{26}-26(c$ 0.10, MeOH); m.p. $158-162^{\circ} \mathrm{C}$; UV (MeOH) $\lambda_{\max }(\log \varepsilon) 210$ (4.34), 242 (4.21), 250 (4.23), 288 (4.08) nm; high-resolution electron impact mass spectrometry $\mathrm{m} / \mathrm{z}[\mathrm{M}]^{+} 248.1046$ (calcd. for $\mathrm{C}_{14} \mathrm{H}_{16} \mathrm{O}_{4}, 248.1043$ ). IR $v_{\max }$ (film) 3151-3398 (OH group), 2972, 2931, 2881, 1645 (C=O), 1577, 1396, 1340, 1276, $1159 \mathrm{~cm}^{-1}$. For ${ }^{1} \mathrm{H}\left(\mathrm{CD}_{3} \mathrm{OD}_{3}, 400 \mathrm{MHz}\right),{ }^{13} \mathrm{C}$ $\left(\mathrm{CD}_{3} \mathrm{OD}_{3}, 100 \mathrm{MHz}\right), \mathrm{HH}-\mathrm{COSY}$ and $\mathrm{HMBC}$, see Table 1 and Supplementary Figures S3 and S4.

The antimicrobial activity of mycoleptione was evaluated by the procedure of the Clinical and Laboratory Standards Institute (CLSI) using Escherichia coli ATCC 25922, Pseudomonas aeruginosa ATCC 27853, Staphylococcus aureus ATCC 29923, Enterococcus faecalis ATCC 29212, Saccharomyces cerevisiae ATCC 6275, Candida albicans OUT 6266, Aspergillus niger ATCC 6275, Rhizopus oryzae ATCC10404 and Geotrichum candidum IFO4598 as indicator strains. ${ }^{16}$ However, no activities against these strains were detected (MIC $>512 \mu \mathrm{g} \mathrm{ml}^{-1}$ for antibacterial and $>128 \mu \mathrm{g} \mathrm{ml}^{-1}$ for anti-yeast and antifungal assays). Subsequently, the antioomycetes activity against Aphanomyces cochlioides AC-5 and Phytophthora sojae P6497 was measured by the agar plug method of Strobel with some modifications. ${ }^{17}$ Mycoleptione showed moderate activity against $A$. cochlioides, with an MIC value of $6.25 \mu \mathrm{g} \mathrm{ml}^{-1}$, but had no effect against $P$. sojae even at $100 \mu \mathrm{g} \mathrm{ml}^{-1}$.

In addition to the determination of $\mathbf{1}$, compound $\mathbf{2}$ was identified as 7-epiaustdiol based on its spectroscopic data (Figure 1 and Supplementary Figures S5, S6, S7 and S9)..$^{18,19}$ The antioomycetes assay revealed that 2 displayed strong activity against both 
A. cochlioides and $P$. sojae, with MIC values of $<0.39$ and $1.56 \mu \mathrm{g} \mathrm{ml}^{-1}$, respectively. This is the first report that 7-epiaustdiol (2) is produced in this genus and has the antioomycete activities.

Antioomycetes assay: the MIC of $\mathbf{1}$ and $\mathbf{2}$ against two plant pathogenic oomycetes, A. cochlioides AC-5 and P. sojae P6497, was determined with a 96-well microplate (Zellkultur Test Plate 96F; Zellkultur, Basel, Switzerland) using the method modified from Strobel et al. ${ }^{17}$ The compound dissolved in methanol by serial twofold dilution $(3 \mu \mathrm{l})$ was dispensed into a microplate containing $300 \mu \mathrm{l}$ of potato dextrose broth and V8 for A. cochlioides and P. sojae, respectively, for final concentration ranging from 0.39 to $100 \mu \mathrm{g} \mathrm{ml}^{-1}$. An agar plug ( $5 \mathrm{~mm}$ diameter) from the 7 -day-old culture of the oomycetes was placed into each well. The antioomycetes activity was evaluated after incubation for 5-6 days by comparing with a negative control containing culture broth and microorganisms without the compounds. Hygromycin B dissolved in $\mathrm{MeOH}$ was used as the positive control, and $3 \mu \mathrm{l}$ of $\mathrm{MeOH}$ was used as the negative control. The lowest concentration of the compound under which the microorganism could not grow was considered the MIC.

\section{ACKNOWLEDGEMENTS}

This study was supported in part by a scholarship from the Ministry of Education, Culture, Sports, Science and Technology (MEXT) of Japan to RS and by funds from the joint program in the field of biotechnology under the Japan Society for the Promotion of Science (JSPS) and the National Research Council of Thailand (NRCT) to TN, HK and SK.

1 Strobel, G. A. Endophytes as sources of bioactive products. Microbes Infect. 5, 535-544 (2003).

2 Guo, B., Wang, Y., Sun, X. \& Tang, K. Bioactive natural products from endophytes: a review. Appl. Biochem. Microbiol. 44, 136-142 (2008).

3 Tansuwan, S. et al. Antimalarial benzoquinones from an endophytic fungus, Xylaria sp. J. Nat. Prod. 70, 1620-1623 (2007).
4 Pongcharoen, W., Rukachaisirikul, V., Phongpaichit, S., Rungjindamai, N. \& Sakayaroj, J. Pimarane diterpene \& cytochalasin derivatives from the endophytic fungus Eutypella scoparia PSU-D44. J. Nat. Prod. 69, 856-858 (2006).

5 Sappapan, R. et al. 11-Hydroxymonocerin from the plant endophytic fungus Exserohilum rostratum. J. Nat. Prod. 71, 1657-1659 (2008).

6 Rukachaisirikul, V., Sommart, U., Phongpaichit, S., Sakayaroj, J. \& Kirtikara, K. Metabolites from the endophytic fungus Promopsis sp. PSU-D15. Phytochemistry 69, 783-787 (2008).

7 Siriwach, R. et al. Xylaropyrone, a new $\gamma$-pyrone from the endophytic fungus Xylaria feejeensis MU18. J. Antibiot. 64, 217-219 (2011).

8 Dweck, A. C. \& Cavin, J.-P. Andawali (Tinospora cripa): a review (2006). http:// www.dweckdata.com/published_papers/Tinospora_crispa.pdf.

9 Gunner, H. B. Microbiological control of Eurasian watermilfoil. Alfred cofrancesco aquatic plant control research program, Misc. Paper A-83-4. US army engineer waterways experiment station (Vicksburg, MS, 1983).

10 Nelson, L. S. \& Shearer, J. F. 2,4-D \& Mycoleptodiscus terrestris for control of Eurasian watermilfoil. J. Aquat. Plant Manage 43, 29-34 (2005).

11 Shearer, J. F. \& Jackson, M. A. Liquid culturing of microsclerotia of Mycoleptodiscus terrestris, a potential biological control agent for the management of hydrilla. Biol. Control 38, 298-306 (2006).

12 Andrioli, W. J. et al. The fungal metabolite eugenitin as additive for Aspergillus niveus glucoamylase activation. J. Mol. Catal. B-Enzym. 74, 156-161 (2011).

13 Kashiwada, Y., Nonaka, G. I. \& Nishioka, I. Studies on Rhubarb (Rhei Rhizoma). V. isolation \& characterization of chromone \& chromanone derivatives. Chem. Pharm. Bull. 32, 3493-3500 (1984).

$14 \mathrm{Xu}$, J. et al. Chromones from the endophytic fungus Pestalotiopsis sp. isolated from the chinese mangrove plant Rhizophora mucronata. J. Nat. Prod. 72, 662-665 (2009).

15 Hoye, T. R., Jeffrey, C. S. \& Shao, F. Mosher ester analysis for the determination of absolute configuration of stereogenic (chiral) carbinol carbons. Nat. Protoc. 2, 2451-2458 (2007).

16 Clinical \& Laboratory Standards Institute (CLSI), 2007. (a) Methods for dilution antimicrobial susceptibility tests for bacteria that grow aerobically-seventh edition; approved standard M07-07, (b) Reference method for broth dilution antifungal susceptibility testing of yeasts-third edition; approved standard M27-A3 (c) Reference method for broth dilution antifungal susceptibility testing of filamentous fungi-second edition; approved standard M38-A2, Wayne, PA.

17 Strobel, G. et al. Oocydin A, a chlorinated macrocyclic lactone with potent antioomycete activity from Serratia marcescens. Microbiology 145, 3557-3564 (1999).

18 Vleggaar, R., Steyn, P. S. \& Nagel, D. W. Constitution \& absolute configuration of austdiol, the main toxic metabolite from Aspergillus ustus. J. Chem. Soc., Perkin. Trans. 1 1, 45-49 (1974).

$19 \mathrm{Liu}, \mathrm{F}$. et al. The bioactive metabolites of the mangrove endophytic fungus Talaromyces sp. ZH-154 isolated from Kandelia candel (L.) Druce. Planta. Med. 76, 185-189 (2010).

Supplementary Information accompanies the paper on The Journal of Antibiotics website (http://www.nature.com/ja) 